\title{
ANALISIS DAN PENGEMBANGAN SISTEM INFORMASI GEOGRAFIS RADIO DAN TELEVISI SIARAN PROPINSI JAMBI BERBASIS WEB PADA BALAI MONITOR SFR JAMBI
}

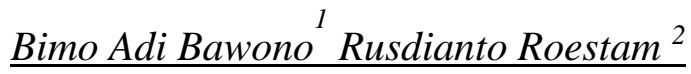 \\ Program Studi Magister Sistem Informasi, STIKOM Dinamika Bangsa, Jambi \\ Jl. Jendral Sudirman, Kec. The Hok, (0741) 35095 \\ E-mail: bimo.lokajambi@gmail.com,rroestam@gmail.com ${ }^{2}$
}

\begin{abstract}
The problems that faced by Balai Monitor SFR Kelas II Jambi Office is they have difficulty in locating, identifying and analyzing of radio frequency interference in radio and television broadcasting. This problem caused by their radio and television broadcasting data still on excel form and not yet available a georgraphic information system which show the location and technical data of the radio and television broadcast. The aims of this study are to analyze the needs of geographic information system required by Balai Monitor SFR Kelas II Jambi Office, then design it using UML (Unifed Modeling Language) and develop it in the form of geographic information system webisite using php, maria $d b$, and google map api application. The result of this study is a web-based geographic information system for broadcasting radio and television in Jambi Province, with location search, identification and analysis of frequency interference features that have been successfully tested, so it can be used to deal with problems that have been faced by Balai Monitor SFR Kelas II Jambi Office.
\end{abstract}

Keywords: Geographic Information System, Radio and Television, Jambi, UML, Google Map API.

\begin{abstract}
Abstrak
Permasalahan yang dihadapi oleh Kantor Balai Monitor SFR Kelas II Jambi adalah, petugas pengendali frekuensi radio mengalami kesulitan dalam pencarian lokasi, identifikasi dan analisis gangguan frekuensi radio dan televisi siaran karena data radio dan televisi siaran yang ada masih berupa data tabel excel dan belum tersedia sistem informasi yang memetakan lokasi dan data teknis radio dan televisi siaran. Penelitian ini bertujuan menganalisa kebutuhan sistem informasi geografis yang diperlukan oleh Kantor Balai Monitor SFR Kelas II Jambi, kemudian merancangnya dengan menggunakan UML (Unifed Modeling Language) dan mengembangkannya dalam bentuk aplikasi website sistem informasi geografis menggunakan aplikasi php, maria db, dan google map api. Hasil dari penelitian ini, berupa website sistem informasi geografis radio dan televisi siaran di Propinsi Jambi, dengan fitur pencarian lokasi, identifikasi dan analisis gangguan frekuensi yang telah berhasil diuji, sehingga dapat digunakan untuk menangani permasalahan yang selama ini dihadapi oleh petugas pengendali frekuensi radio Kantor Balai Monitor SFR Jambi.
\end{abstract}

Kata kunci: Sistem Informasi Geografis, Radio dan Televisi, Jambi, UML, Google Map API.

(C) 2019 Jurnal Manajemen Sistem Informasi.

Jurnal Manajemen Sistem Informasi Vol.4, No.2, Juni 2019 


\section{Pendahuluan}

Balai Monitor Spektrum Frekuensi Radio Jambi adalah intansi pemerintah yang melayani masyarakat dalam bidang pengawasan dan pengendalian penggunaan spektrum frekuensi radio, salah satunya adalah pada dinas penyiaran radio dan televisi siaran di Propinsi Jambi. Jumlah lembaga penyiaran baik radio maupun televisi siaran yang di Propinsi Jambi.

Menurut data Sistem Informasi Manajemen - Spektrum (SIM-S) pada bulan Oktober 2017 Berjumlah 73 (tujuh puluh tiga) buah Lembaga Siaran, jumlah ini bertambah setiap tahunnya. Data mengenai perizinan lembaga penyiaran yang ada di Kantor Balai Monitor SFR Jambi masih berupa data tabel dengan format file excel, bersumber dari database SIM-S yang berada di pusat Kantor Kementerian Kominfo, Jl. Medan Merdeka Barat No.17, Jakarta 10110, Indonesia. Kantor Balai Monitor SFR Jambi saat ini masih belum memiliki sistem informasi geografis yang dapat memetakan lokasi seluruh lembaga penyiaran yang ada di Propinsi Jambi, sehingga petugas pengendali frekuensi radio mengalami kesulitan dalam pencarian lokasi lembaga penyiaran, identifikasi, dan analisis gangguan frekuensi lembaga penyiaran. Misalnya ketika petugas pengendali frekuensi radio ingin mengetahui lokasi radio siaran / televisi siaran dilapangan berdasarkan data SIM-S, maka petugas harus mencari dan mencatat koordinat lokasi radio siaran / televisi siaran yang ingin dituju kemudian memasukkan data koordinat tersebut pada perangkat GPS lalu memilih menu tracking rute untuk mendapatkan petunjuk arah untuk menujur radio / televisi siaran tersebut.

Atas latar belakang masalah tersebut, penulis tertarik untuk mengkaji lebih dalam permasalahan yang ada dan dituangkan dalam bentuk penulisan thesis dengan judul "Analisis dan Pengembangan Sistem Informasi Geografis Radio dan Televisi Siaran Propinsi Jambi Berbasis Web Pada Balai Monitor SFR Jambi".

Penelitian ini bertujuan menganalisa kebutuhan sistem informasi geografis yang diperlukan oleh Kantor Balai Monitor SFR Kelas II Jambi, kemudian merancangnya dengan menggunakan $U M L$ (Unifed Modeling Language) dan mengembangkannya dalam bentuk aplikasi website sistem informasi geografis menggunakan aplikasi php, maria $\mathrm{db}$, dan google map api.

\section{Tinjauan Pustaka/Penelitian Sebelumnya}

Romi Eko Saputra, 2015. Dalam penelitian yang berjudul analisis dan perancangan sistem informasi geografis BTS pada Dinas Perhubungan Komunikasi dan Informatika Kabupaten Tanjung Jabung Timur yang memetakan lokasi BTS untuk operator seluler di Kabupaten Tanjung Jabung timur dengan tujuan agar operator dan provider dapat mengetahui secara online posisi dan wilayah BTS yang ada di Kabupaten Tanjung Jabung Timur dan juga memudahkan dalam pegawai DISHUBKOMINFO dalam segi pengawasan dan penataan BTS yang ada di Kabupaten Tanjung Jabung Timur. Perbedaan penelitian yang di lakukan Romi Eko Saputra dengan penelitian yang di lakukan oleh peneliti terdapat pada obyek pemetaan, instansi tempat penelitian dan dukungan aplikasi tracking route. Obyek pemetaan yang digunakan penulis adalah Radio dan Televisi Siaran pada Propinsi Jambi, instansi tempat penelitian yang dilakukan oleh penulis adalah Kantor Balai Monitor Spektrum Frekuensi Radio Jambi dan serta dikembangkannya fitur tracking route.

Iman Jati Kusuma Sadewi.2015. Dalam penelitian yang berjudul Analisis dan Perancangan Sistem Informasi Geografis Panduan Objek Wisata Wilayah Provinsi Jambi Berbasis Android, dalam penelitiannya Iman berpendapat bahwa Sistem Informasi Geografis (SIG) sebagai salah satu bidang ilmu yang tergolong baru, saat ini telah mampu menyelesaikan masalah, baik untuk masalah pencarian rute terpendek (shortest path) maupun masalah TSP (travelling salesman problem). Pencarian rute terpendek merupakan masalah dalam kehidupan sehari-hari, berbagai kalangan menemui masalah yang sama dalam pencarian rute terpendek (shortest path) dengan variasi yang berbeda, dimana untuk penentuan rute terpendek diperlukan ketepatan dalam penentuan jalur terpendek antar suatu titik atau lokasi yang diinginkan. Hasil penentuan jalur terpendek nantinya akan menjadi pertimbangan dalam menunjukkan jalur yang ditempuh oleh masyarakat dengan bantuan sistem informasi geografis. Perbedaan penelitian yang di lakukan Iman Jati Kusuma Sadewi dengan penelitian yang di lakukan oleh peneliti terdapat pada obyek pemetaan, instansi tempat penelitian, basis rancangan aplikasi dan metode pengembangan sistem. Obyek pemetaan yang digunakan penulis adalah Radio dan Televisi Siaran pada Propinsi Jambi, instansi tempat penelitian yang dilakukan oleh penulis adalah Kantor Balai Monitor Spektrum Frekuensi Radio Jambi, basis rancangan aplikasi yang dikembangkan penulis adalah berbasis web, dan metode pengembangan sistemnya menggunakan metode waterfall. 


\section{Metodologi}

A. Alur Penelitian

Adapun kerangka kerja yang penulis lakukan dalam penelitian ini adalah :

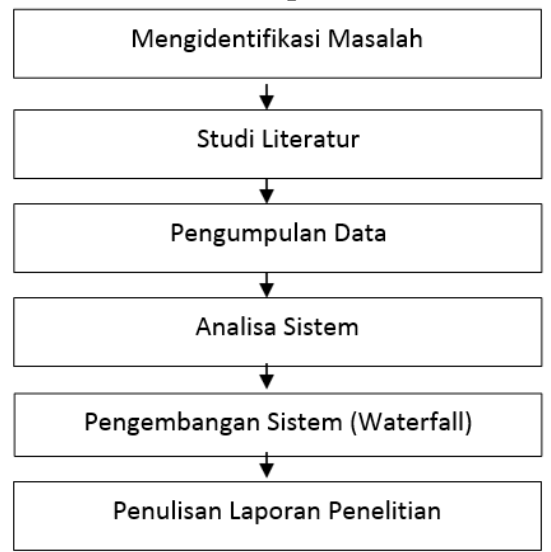

Gambar 3.1. Alur penelitian

Berikut ini uraian alur penelitian berdasarkan gambar 3.1, yaitu:

1. Mengidentifikasi Masalah

Dalam tahapan ini, peneliti mengidentifikasi masalah yang ada yaitu merumuskan masalah yang akan diteliti. Dengan adanya perumusan masalah, maka penelitian akan menjadi jelas dan terarah.

2. Studi literatur

Mempelajari dan memahami teori-teori yang menjadi pedoman dan referensi dalam penyelesaian masalah yang akan dibahas dalam penelitian ini dan mempelajari penelitian yang terkait dengan masalah yang sedang diteliti.

3. Pengumpulan Data

Untuk mendapatkan informasi dan data-data yang akurat, penulis menggunakan beberapa teknik pengumpulan data sebagai berikut :

1) Pengamatan (observation)

Penelitian dengan metode observasi ini dilakukan dengan melakukan pengamatan langsung terhadap objek yang akan diteliti (berupa data SIM-S) yang bertujuan untuk mengetahui secara langsung mengenai sistem informasi geografis radio dan televisi siaran pada Kantor Balai Monitor SFR Jambi.

2) Wawancara (Interview)

Penulis melakukan penelitian lapangan dengan cara melakukan wawancara kepada para petugas pengendali frekuensi radio yang ada di Kantor Balai Monitor SFR Jambi yang berkaitan untuk memperoleh data-data yang dibutuhkan oleh penulis. Hal ini dilakukan agar penulis mengetahui kegiatan apa saja yang dilakukan. Untuk memperoleh data yang akurat serta relevan agar dapat menghasilkan suatu rancangan website yang sesuai kebutuhan. Wawancara yang dilakukan dengan dua bentuk, yaitu wawancara terstruktur (dilakukan melalui pertanyaan-pertanyaan yang telah disiapkan sesuai dengan permasalahan yang akan diteliti). Sedangkan wawancara tidak terstruktur (wawancara dilakukan apabila adanya jawaban berkembang di luar sistem permasalahan).

4. Analisa Sistem

Pada langkah ini dilakukan analisa terhadap kebutuhan sistem informasi geografis yang ada di Kantor Balai Monitor SFR Jambi, fitur apa saja yang diinginkan, data teknis radio dan televisi siaran apa saja yang ingin ditampilkan pada sistem informasi geografis tersebut.

Selain itu juga dilakukan analisa terhadap interaksi-interaksi yang terjadi di dalam sistem informasi geografis tersebut yang nantinya akan digambarkan dalam model UML, yaitu : diagram Use Case, Diagram Class. 
5. Pengembangan Sistem

Model Pengembangan Air Terjun, merupakan paradigma model pengembangan perangkat lunak paling tua, dan paling banyak dipakai. Model ini mengusulkan sebuah pendekatan perkembangan perangkat lunak yang sistematik dan sekunsial yang dimulai pada tingkat dan kemajuan sistem pada seluruh tahapan analisis, desain , pembuatan prototype dan pengujian.

\section{Hasil dan Pembahasan}

\subsection{Analisis Sistem Yang Berjalan}

Data mengenai perizinan lembaga penyiaran yang ada di Kantor Balai Monitor SFR Jambi masih berupa data tabel dengan format file excel, bersumber dari database SIM-S yang berada di pusat Kantor Kementerian Kominfo, Jl. Medan Merdeka Barat No.17, Jakarta 10110, Indonesia. Kantor Balai Monitor SFR Jambi saat ini masih belum memiliki sistem informasi geografis yang dapat memetakan lokasi seluruh lembaga penyiaran yang ada di Propinsi Jambi, sehingga petugas pengendali frekuensi radio mengalami kesulitan dalam pencarian lokasi lembaga penyiaran, identifikasi, dan analisis gangguan frekuensi lembaga penyiaran. Misalnya ketika petugas pengendali frekuensi radio ingin mengetahui lokasi radio siaran / televisi siaran dilapangan berdasarkan data SIM$\mathrm{S}$, maka petugas harus mencari dan mencatat koordinat lokasi radio siaran / televisi siaran yang ingin dituju kemudian memasukkan data koordinat tersebut pada perangkat GPS lalu memilih menu tracking rute untuk mendapatkan petunjuk arah untuk menujur radio / televisi siaran tersebut.

Begitu juga pada saat kegiatan monitoring spektrum frekuensi radio yang ditujukan untuk keperluan identifikasi pengguna frekuensi radio, ketika termonitor suatu frekuensi radio / televisi siaran " $\mathrm{X}$ " ( hanya diketahui frekuensi nya misal $98 \mathrm{MHz}$ ), maka petugas harus mencocokkan frekuensi tersebut dengan data tabel SIM-S untuk diketahui identitas nya. Dalam proses pencocokan data untuk memperoleh informasi mengenai identitas radio / televisi siaran tersebut memerlukan waktu yang cukup lama.

Kesulitan ini juga terjadi pada saat penanganan gangguan spektrum frekuensi radio / televisi siaran, untuk melakukan analisa gangguan petugas pengendali frekuensi radio harus memploting koordinat yang ada pada data tabel SIM-S ke dalam aplikasi pemetaan, misalnya Google Earth, hal ini tentunya juga memerlukan waktu yang tidak sedikit karena petugas pengendali frekuensi radio harus mencari koordinat radio / televisi siaran yang ada pada data SIM-S kemudian memasukkan koordinat tersebut secara manual satu persatu ke dalam aplikasi pemetaan.

\subsection{Analisis Kebutuhan Sistem}

Pada analisis sistem, pengidentifikasian kebutuhan sistem dapat di bagi menjadi 2 yaitu :

\section{A. Kebutuhan Fungsional Sistem}

Pemodelan fungsional sistem menggambarkan proses atau fungsi yang harus dikerjakan oleh sistem untuk melayani kebutuhan pengguna (user). Berdasarkan kebutuhan diketahui bahwa aktor yang menggunakan sistem adalah Admin dan User dalam hal ini user adalah PPFR (petugas pengendali frekuensi radio), maka fungsi utama yang harus ada dalam sistem informasi geografis radio dan televisi siaran berbasis web pada Balai Monitor Spektrum Frekuensi Radio Kelas II Jambi adalah sebagai berikut :

\subsection{Perancangan Sistem}

\subsubsection{Use Case Diagram}

Berdasarkan asumsi yang digunakan dapat digambarkan diagram use case Sistem informasi geografis radio dan televisi siaran Berbasis Web pada Balai Monitor Spektrum Frekuensi Radio Kelas II Jambi adalah sebagai berikut: 


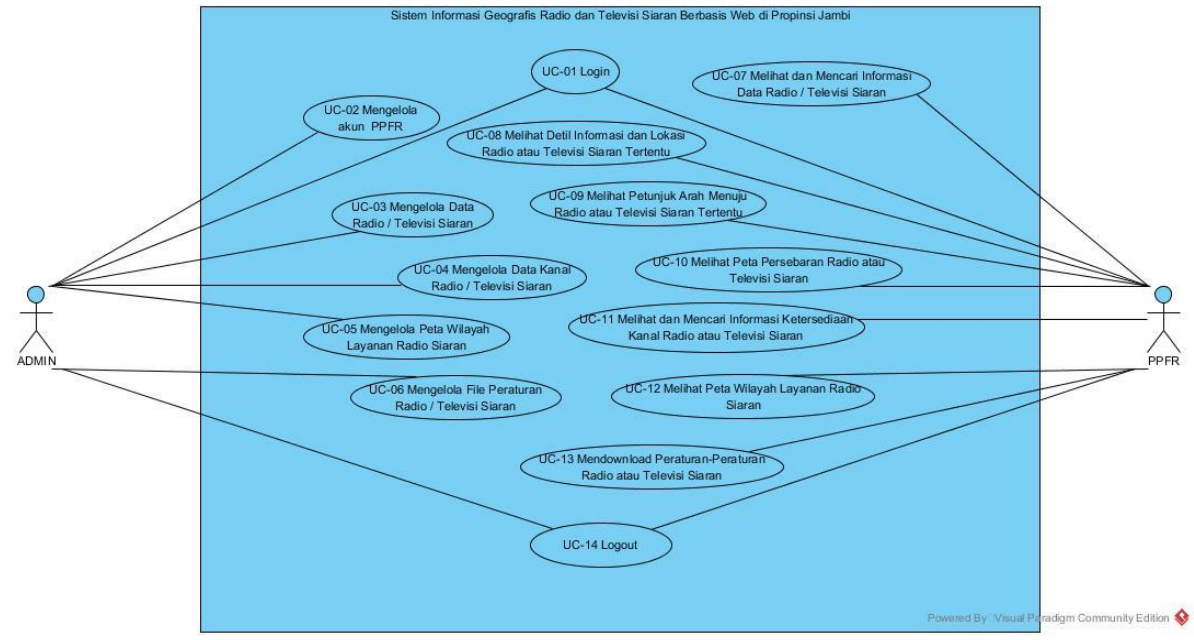

Gambar 4.1 Diagram Use Case SIG radio dan televisi siaran berbasis web

\subsubsection{Class Diagram}

Analisis kebutuhan data untuk perangkat lunak yang akan dibuat dapat digambarkan dengan class diagram seperti terlihat pada gambar dibawah ini :

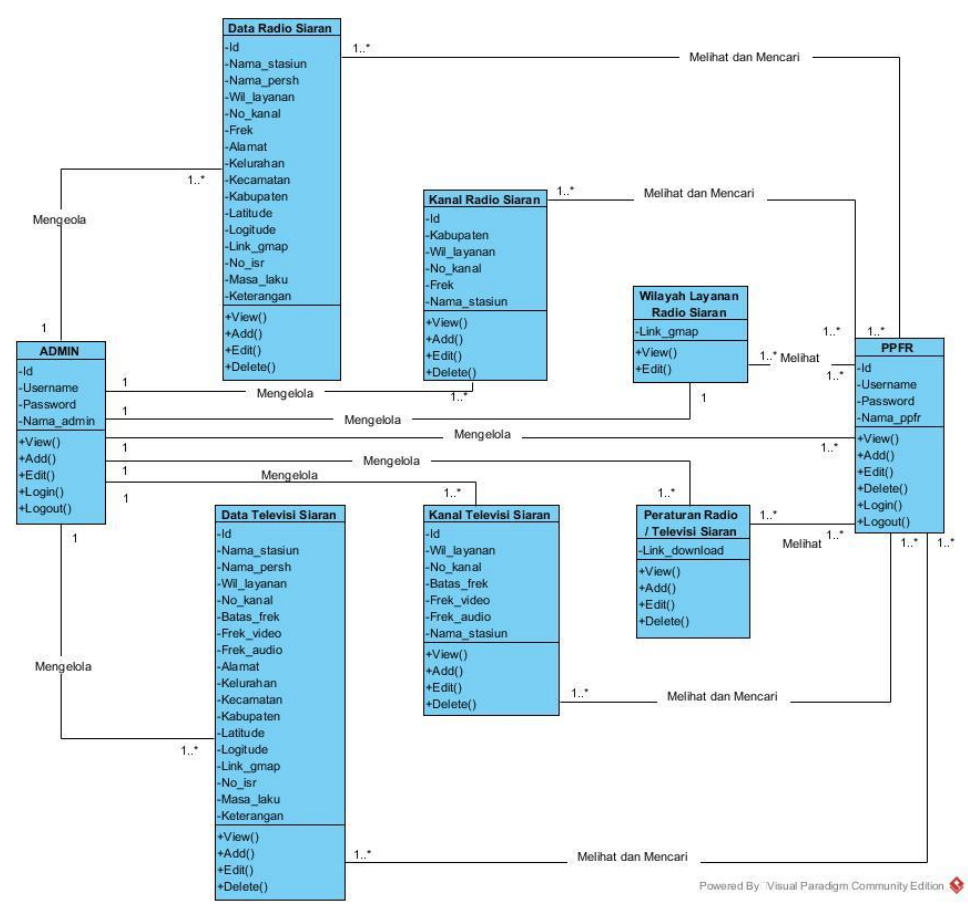

Gambar 4.2 Diagram Class SIG radio dan televisi siaran berbasis web

\subsection{Implementasi Hasil Perancangan}

1. Implementasi Halaman Login

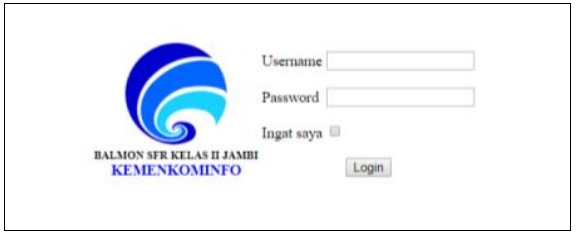


Gambar 4.3 Implementasi Halaman Login

Admin dan PPFR dapat memasuki sistem dengan mengisikan username dan password kemudian klik login, admin akan memasuki halaman utama admin dan PPFR akan memasuki halaman utama pengguna sistem informasi geografis radio dan televisi siaran berbasis web di Propinsi Jambi

2. Implementasi Halaman Utama

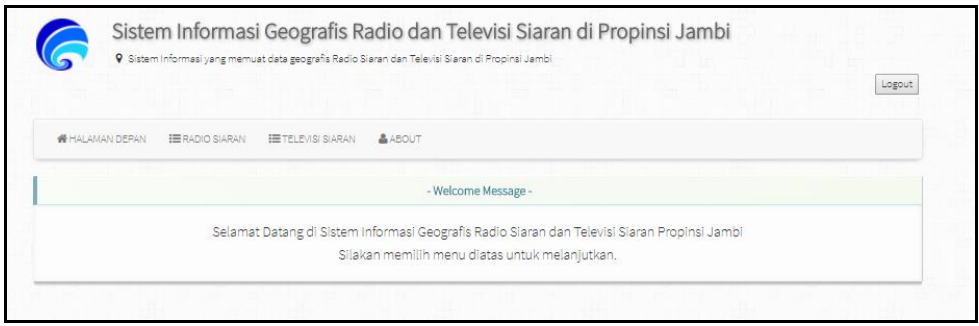

Gambar 4.4 Implementasi Halaman Utama

PPFR dapat memilih menu yang tersedia yaitu Radio Siaran yang terdiri dari Data Radio Siaran, Detil dan Lokasi Radio Siaran, Peta Persebaran Radio Siaran, Daftar Kanal Radio Siaran, Wilayah Layanan Radio Siaran, dan Peraturan Radio Siaran. Sedangakan menu Televisi Siaran terdiri dari Data Televisi Siaran, Detil dan Lokasi Televisi Siaran, Peta Persebaran Televisi Siaran, Daftar Kanal Televisi Siaran dan Peraturan Televisi Siaran.

3. Implementasi Halaman Data Radio Siaran

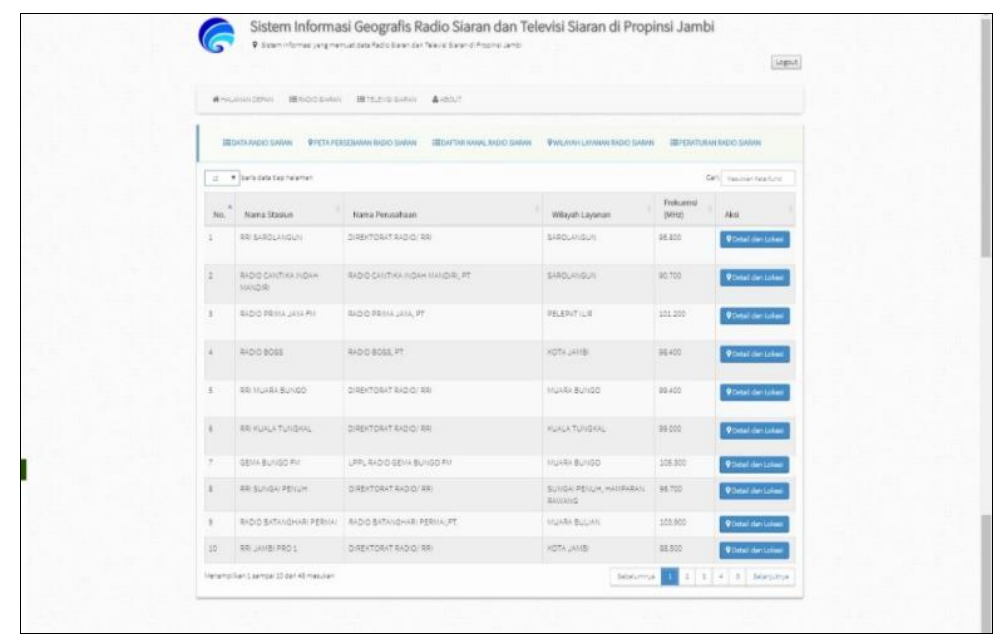

Gambar 4.5 Implementasi Halaman Data Radio Siaran

PPFR dapat mencari atau memfilter radio siaran berdasarkan keyword tertentu, data yang dicari akan automatis tampir pada tabel data grid, kemudian PPFR dapat menekan tombol detil dan lokasi untuk melihat data radio siaran secara detil dan melihat peta lokasi radio siaran tersebut. 
4. Implementasi Halaman Detil Lokasi Radio Siaran

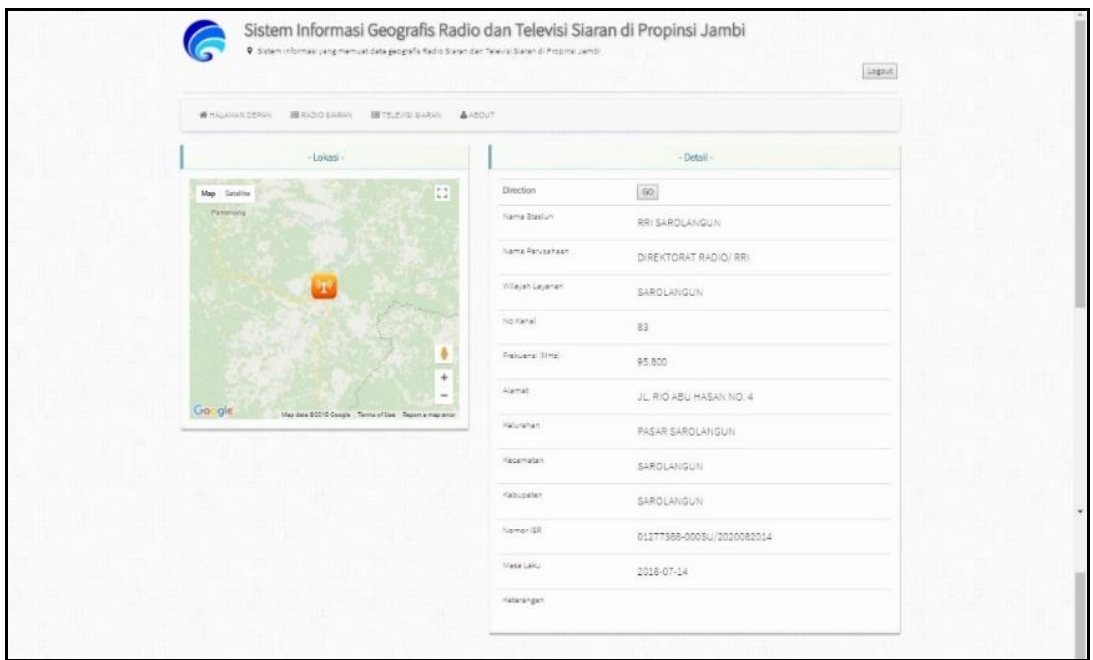

Gambar 4.6 Implementasi Halaman Detil Lokasi Radio Siaran

Halaman ini menampilkan detil informasi radio siaran yang telah dicari beserta tampilan peta lokasi radio siaran tersebut. Halaman ini dibangun menggunakan javascript dengan content dari google map api.

5. Implementasi Halaman Peta Persebaran Radio Siaran

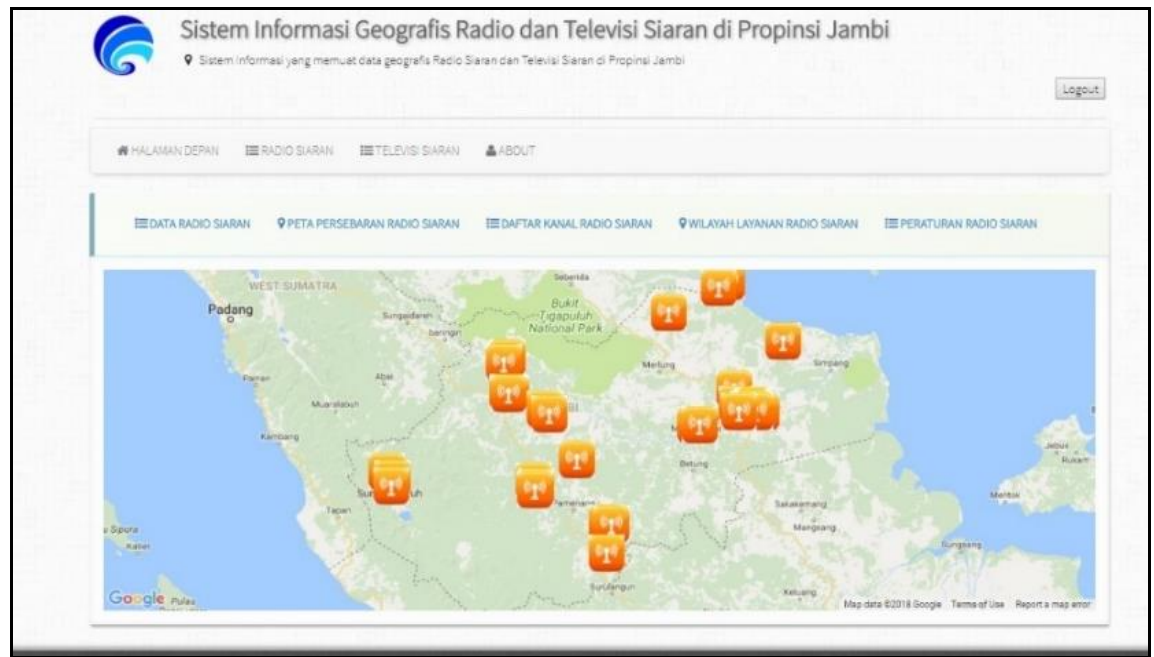

Gambar 4.7 Implementasi Halaman Peta Persebaran Radio Siaran

PPFR dapat mengetahui sejauh mana persebaran radio siaran yang ada di Propinsi Jambi, sehingga dapat digunakan untuk analisa kemungkinan gangguan frekuensi radio yang akan terjadi, serta pengendalian jumlah radio yang ada agar terjadi persaingan yang sehat dalam dunia bisnis penyiaran di Propinsi Jambi. 
6. Implementasi Halaman Daftar Kanal Radio Siaran

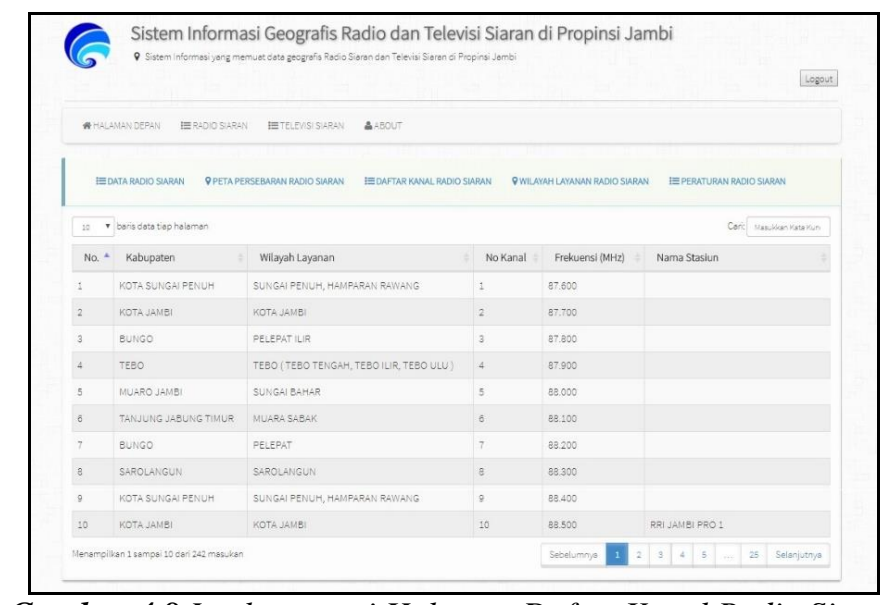

Gambar 4.8 Implementasi Halaman Daftar Kanal Radio Siaran

PPFR dapat mencari wilayah layanan radio siaran yang ada lengkap dengan informasi penggunaan kanalnya. Selain manfaat tersebut, PPFR juga dapat mencari informasi kanal yang kosong pada wilayah layanan tertentu menggunakan bantuan fitur pencarian pada sudut kanan di atas tabel data grid.

7. Implementasi Halaman Wilayah Layanan Radio Siaran

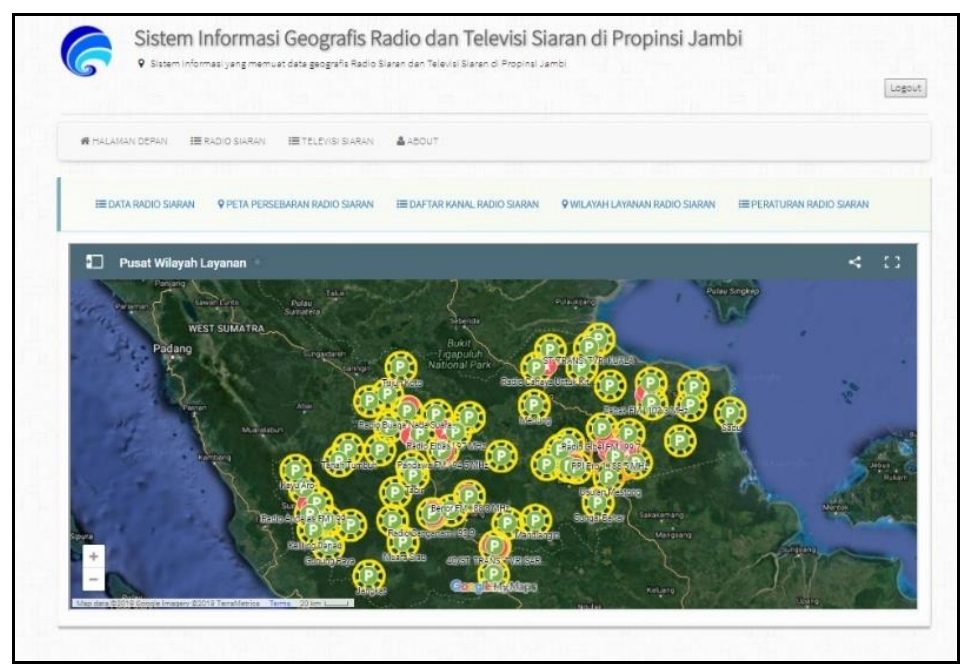

Gambar 4.9 Implementasi Halaman Wilayah Layanan Radio Siaran

PPFR dapat melihat peta wilayah layanan radio siaran secara interaktif menggunakan link google map, tampilan ini dapat digunakan untuk analisa gangguan frekuensi radio siaran, untuk penentuan titik lokasi pengukuran kualitas wilayah layanan radio, serta untuk menentukan wilayah layanan bagi radio siaran yang akan mengajukan Izin Stasiun Radio (baru berdiri). 
8. Implementasi Halaman Peraturan Radio Siaran

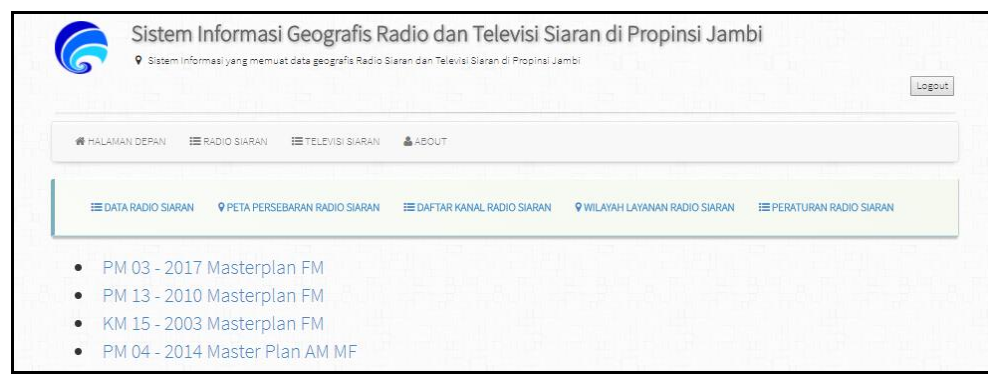

Gambar 4.10 Implementasi Halaman Peraturan Radio Siaran

PPFR dapat mendownload dan melihat peraturan peraturan tentang radio siaran yang berlaku.

9. Implementasi Halaman Data Televisi Siaran

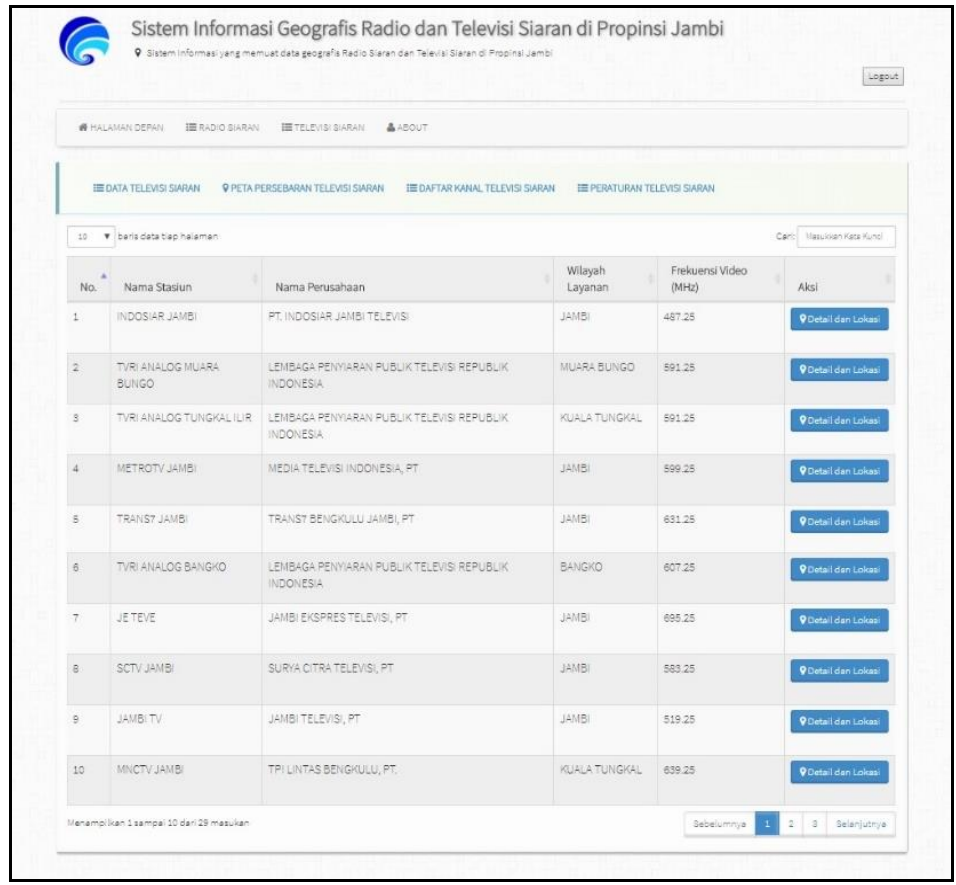

Gambar 4.11 Implementasi Halaman Data Televisi Siaran

PPFR dapat mencari atau memfilter televisi siaran berdasarkan keyword tertentu, data yang dicari akan automatis tampir pada tabel data grid, kemudian PPFR dapat menekan tombol detil dan lokasi untuk melihat data televisi siaran secara detil dan melihat peta lokasi televisi siaran tersebut. 
10. Implementasi Halaman Detil Lokasi Televisi Siaran

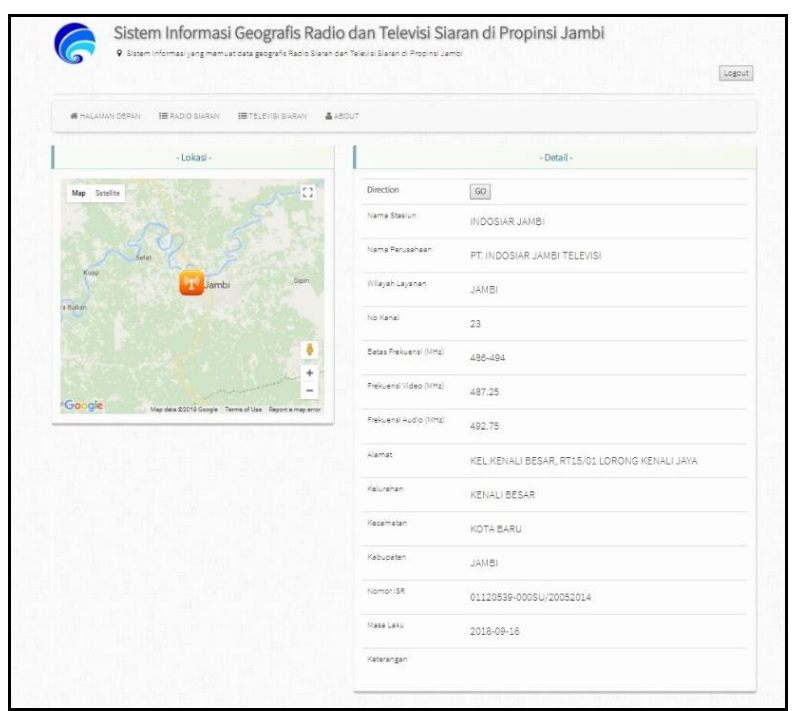

Gambar 4.12 Implementasi Halaman Detil Lokasi Televisi Siaran

Halaman ini menampilkan detil informasi televisi siaran yang telah dicari beserta tampilan peta lokasi televisi siaran tersebut. Halaman ini juga dibangun menggunakan javascript dengan content dari google map api.

11. Implementasi Halaman Peta Sebaran Televisi Siaran

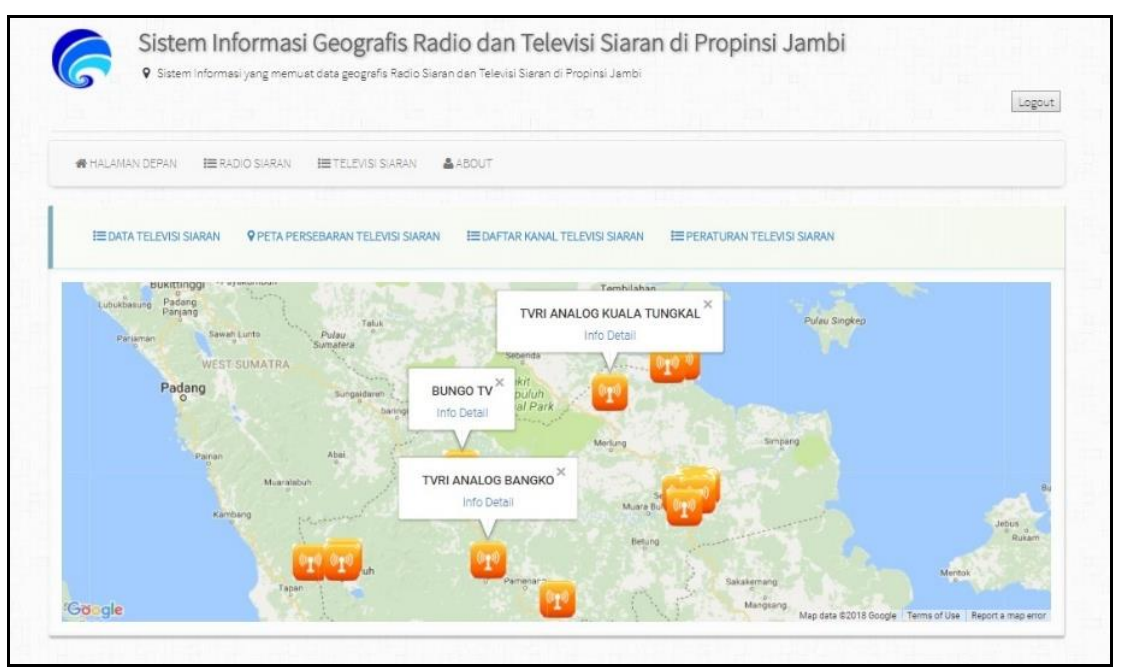

Gambar 4.13 Implementasi Halaman Peta Sebaran Televisi Siaran

PPFR dapat mengetahui sejauh mana persebaran televisi siaran yang ada di Propinsi Jambi, sehingga dapat digunakan untuk analisa kemungkinan gangguan frekuensi televisi siaran yang akan terjadi, serta pengendalian jumlah televisi yang ada agar terjadi persaingan yang sehat dalam dunia bisnis penyiaran di Propinsi Jambi. 


\section{Kesimpulan dan Saran}

\subsection{Simpulan}

Berdasarkan bab sebelumnya yakni hasil penelitian dan pembahasan, maka dapat diperoleh kesimpulan sebagai berikut :

1. Permasalahan yang dihadapi oleh Kantor Balai Monitor SFR Kelas II Jambi adalah, petugas pengendali frekuensi radio mengalami kesulitan dalam pencarian lokasi, identifikasi dan analisis gangguan frekuensi radio dan televisi siaran karena data radio dan televisi siaran yang ada masih berupa data tabel excel dan belum tersedia sistem informasi yang memetakan lokasi dan data teknis radio dan televisi siaran.

2. Sistem ini dirancang menggunakan aplikasi visual paradigm versi 13 community edition untuk menangani diagram UML, dan aplikasi balsamiq mockup 3.1.5 untuk menangani desain tampilanya. Pada tahap pengembangannya penulis menggunakan aplikasi XAMPP server untuk menangani server PHP dan database Maria DB, sedangkan untuk penulisan kode nya, penulis menggunakan aplikasi sublime text 3. Pada bagian pemetaannya penulis menggunakan fasilitas javascript google map api.

3. Dari hasil pengujian sistem informasi geografis radio dan televisi siaran berbasis web di Propinsi Jambi yang telah dilakukan, dengan cara memberikan input ke sistem, secara keseluruhan sistem dapat menghasilkan output yang diinginkan, sebagai contoh ketika memasukkan keyword 101.2 pada menu pencarian data radio siaran, maka sistem menampilkan data teknis dari Radio Prima Jaya FM, begitu juga ketika dilakukan penekanan tombol "Detail dan Lokasi", maka sistem menampilan halaman "Detail dan Lokasi" yang berisikan informasi lengkap mengenai Radio Prima Jaya FM beserta peta lokasi nya. Dari hasil gambaran test diatas maka dapat disimpulkan bahwa sistem yang dibangun telah bekerja dengan baik.

4. Hasil test terhadap fitur pencarian lokasi, identifikasi, dan analisa gangguan frekuensi radio dan televisi siaran menunjukkan bahwa sistem secara keseluruhan telah mampu menjawab permasalahan yang selama ini dialami oleh petugas pengendali frekuensi radio.

\subsection{Saran}

Berdasarkan penelitian yang telah dilakukan, maka saran yang dapat diajukan adalah sebagai berikut:

1. Disarankan kepada Koordinator Jabatan Fungsional Pengendali Frekuensi Radio untuk mengguna sistem yang telah dikembangkan ini untuk mempermudah kegiatan pencarian lokasi, identifikasi dan analisis gangguan frekuensi radio dan televisi siaran karena data radio dan televisi siaran

2. Sistem yang dikembangkan ini memiliki keterbatasan dalam hal update database. Saat ini penambahan, pengubahan dan penghapusan database masih dilakukan dengan cara masuk langsung kedalam alamat database http://localhost/phpmyadmin/ dengan mengimport file database yang berupa file csv. Agar lebih memudahkan admin dalam mengelola database radio / televisi siaran dan data akun PPFR maka, perlu diimplementasikan pembuatan halaman admin yang dikhususkan untuk update data secara mudah, Bagian halaman admin ini telah dimasukkan ke dalam perancangan sistem namun belum diimplementasikan pengembangan menu nya oleh penulis.

3. Untuk pengembangan, sistem ini dapat dikembangkan juga untuk menangani data frekuensi microwave link operator selular yang mana memiliki data teknis yang lebih banyak bila dibandingkan dengan pengguna radio / televisi siaran , sehingga akan dapat memudahkan PPFR dalam menangani pengendalian dan pengawasan frekuensi radio khususnya dalam alokasi frekuensi microwave link.

4. Potensi banyaknya data pengguna frekuensi pada alokasi band penyiaran radio / televisi siaran dapat ditingkatkan menjadi data warehouse yang selanjutnya akan dimanfaatkan untuk aplikasi data mining

\section{Daftar Rujukan}

[1] Anonymous. 2017. Menggunakan MySQL dan PHP dengan Google Maps. https://developers.google.com/maps/documentation/javascript/mysql-to-maps?hl=id. Diakses 
pada tanggal 20 Januari 2018

[2] Barclay, K \& Sa vage, J. 2004. Object-Oriented Design with UML and Java. United States of America : Elseiver.

[3] Darwen, Hugh. 2012. An Introduction to Relational Database Theory (Third Edition). Bookboon.com.

[4] Dennis, Wixom \& Roth. 2012. System Analysis \& Design (Fifth Edition). United States of America : John Wiley \& Sons, Inc.

[5] Irwansyah, Edy. 2013. Sistem Informasi Geografis : Prinsip Dasar dan Pengembangan Aplikasi. Yogyakarta : Digibooks.

[6] Kendall, E. Kenneth; \& Kendall, E. Julie. 2011. Systems Analysis and Design. Eighth Edition. United States of America : Pearson Education Inc.

[7] Kusuma, Iman Jati. 2015. Analisis dan Perancangan Sistem Informasi Geografis Panduan Objek Wisata Wilayah Provinsi Jambi Berbasis Android. Thesis tidak terpubilikasi. Jambi : MSI Stikom Dinamika Bangsa Jambi.

[8] Laudon, Kenneth C dan Laudon, Jane P. 2012. Management Informations Systems : Managing the Digital Firm, (Twelfth Edition). New Jersey : Pearson Education, Inc.

[9] McLeod, Raymond \& Schell, George. 2007. Management Information System (Tenth Edition). New Jersey : Pearson Education, Inc.

[10] O’Brien, A. James, Marakas, George.M. 2006. Management Information System, $10^{\text {th }}$ Edition. McGraw-Hill/Irwin, New York

[11] Peraturan Menteri Kominfo No. 3 Tahun 2017, Tentang rencana induk frekuensi radio untuk keperluan penyelenggaraan radio siaran frequency modulation (Masterplan FM)

[12] Peraturan Menteri Kominfo No. 31 Tahun 2014, Tentang rencana induk (master plan) frekuensi radio penyelenggaraan telekomunikasi khusus untuk keperluan televisi siaran analog pada pita ultra high frequency (Masterplan TV Analog UHF).

[13] Prahasta, Eddy. 2014. Sistem Informasi Geografi (konsep-konsep dasar perspektif geodesi dan geomatika) edisi revisi. Bandung : Informatika Bandung

[14] Pressman. S. Roger. 2010. Software Engineering A Practitioner's Approach 7Th. McGraw-Hill, NewYork

[15] Saputro, Rommy Eko. 2015. Analisis dan perancangan sistem informasi geografis BTS pada Dinas Perhubungan Komunikasi Dan Infromatika Kabupaten Tanjung Jabung Timur. Thesis tidak terpubilikasi. Jambi : MSI Stikom Dinamika Bangsa Jambi.

[16] Silberschatz, Korth \& Sudarshan. 2011. Database System Concept (Sixth Edition). New York : McGraw-Hill Companies, Inc. 